\title{
Bağcılıkta Araştırma-Yayım- Çiftçi İlişkilerinin Değerlendirilmesi: Isparta, Burdur ve Antalya Örneği
}

\author{
Meltem EMRE (D) 1*, Dilek KARAMÜRSEL (iD) 2, Fatma Pınar ÖZTÜRK (D) 2, \\ Alamettin BAYAV ${ }^{\text {ID }}$, Mehmet Ali KIRACI ${ }^{\text {iD }} 3$ \\ ${ }^{1}$ Bornova Zeytincilik Araştırma Enstitüsü Müdürlüğü, İzmir \\ ${ }^{2}$ Meyvecilik Araştırma Enstitüsü Müdürlüğü, Isparta \\ ${ }^{3}$ Tekirdağ Bağcılık Araştırma Enstitüsü Müdürlüğü, Tekirdağ \\ Geliş Tarihi (Received): 01.09.2020, Kabul Tarihi (Accepted): 05.12.2020 \\ $\square$ Sorumlu Yazar (Corresponding author ${ }^{*}$ : meltememre60@gmail.com \\ (C) +902324627073 且 +902324357042
}

\section{ÖZ}

2017-2018 yılları arasında yürütülen bu çalışmada, Türkiye bağcılığında önemli yere sahip Isparta, Burdur, Antalya illerinde bağ yetiştiriciliğiyle uğraşan çiftçi, yayım teşkilatı ve araştırma kuruluşlarının bağcılık eksenli ilişkilerinin belirlenmesi ve sektör paydaşları arasındaki işbirliğinin güçlendirilmesine yönelik öneriler geliştirilmesi amaçlanmıştır. Bu amaçla bağcılık yapan çiftçiler, kamu ve özel sektör yayımcıları ile ilgili illerde bulunan üniversite ve araştırma enstitülerinde bağcılık konusunda çalışma yürüten öğretim üyeleri ve araştırmacıların katılımı ile odak grup toplantısı (OGT) gerçekleştirilmiştir. Yapılan toplantıda, sektör paydaşlarına, bağ yetiştiriciliğinde bölgedeki mevcut durum ve sorunlara ilişkin toplantı öncesinde hazırlanmış olan sorular yöneltilerek konunun tartışııması sağlanmıştır. Çalışmada, araştırma-yayım-çiftçi arasındaki ilişkiler, bağcılık özelinde ele alınmış olsa da, elde edilen sonuçlar ve yapılan öneriler, tüm tarımsal faaliyetlerde sektör paydaşları arasındaki işbirliğinin güçlendirilmesi gerektiğini ve yayımın önemini bir kez daha göstermiştir. Bu nedenle çalışmada bağcılığı, konu açısından örnek tarımsal faaliyet olarak değerlendirmek mümkündür.

Anahtar Kelimeler: Araştırma, bağ yetiştiriciliği, çiftçi, odak grup toplantısı, tarımsal yayım

\section{Evaluation of Research-Extension-Farmer Relations in Viticulture: The Case Study of Isparta, Burdur and Antalya Provinces, Turkey}

\begin{abstract}
In this study carried out in 2017-2018, determining viticulture relations among the vineyard farmers in Isparta, Burdur and Antalya provinces which have an important place in viticulture Turkey, extension service and research institutes and improving the suggestions to strengthen the cooperation among the shareholders of the sector are aimed. The focus group meeting (OGT) was held for this purpose with the participation of public and private sector extension workers, instruction members and researchers who work in viticulture in Isparta, Burdur and Antalya provinces of Turkey. The meeting held by asking questions prepared before the meeting, the sector stakeholders regarding the current situation and problems in the region in vineyard cultivation the subject was discussed. In the study, although the relations between research-extension-farmer was handled in the context of viticulture, the results obtained and the recommendations made once again showed that the cooperation between sector stakeholders in all agricultural activities should be strengthened and the importance of extension. Therefore, it is possible to evaluate viticulture as an exemplary agricultural activity in terms of subject.

Meltem EMRE, https://orcid.org/0000-0003-1141-5888 Dilek KARAMÜRSEL, https://orcid.org/0000-0001-7920-1136 Fatma Pınar ÖZTÜRK, https://orcid.org/0000-0003-2495-0732 Alamettin BAYAV, https://orcid.org/0000-0002-8093-2988 Mehmet Ali KIRACl, https://orcid.org/0000-0001-6604-3765
\end{abstract}


Keywords: Research, vineyard cultivation, farmer, focus group meeting, agricultural extension

\section{GíRiş}

Türkiye, bağcılık için elverişli iklim kuşağı içerisinde yer almakta ve yaklaşık 6000 yıllık bir bağcılık kültürü ile hem yabani hem de kültür asmasına ait çok zengin gen potansiyeline sahip olarak asmanın anavatanı ülkelerden biri sayılmaktadır (Ağaoğlu ve ark.,1997). Türkiye, dünya üzüm üretim alanında 5. ve üretim miktarında 6 . sırada yer almaktadır (FAO, 2020). Bağ alanı ve üzüm üretiminde Ege Bölgesi, ilk sırada yer alırken, bu bölgeyi sırasıyla Akdeniz, Güneydoğu, Orta Anadolu, Marmara, Doğu Anadolu ve Karadeniz Bölgesi izlemektedir (TUIK, 2018). Ege ve Akdeniz Bölgeleri, birim alandan elde edilen verim değerleri bakımından da lider üretim bölgeleridir.

Ancak Türkiye bağcılıktaki üretim potansiyelini kuru üzüm üretim ve ticareti dışında bağcılığın diğer faaliyet dallarında etkin olarak kullanamamaktadır. Özellikle son yıllarda Türkiye bağ alanları yaklaşık \%10 azalmıştır (TUİK, 2018). Bu azalış, geleneksel bir üretim alışkanlığı olmasına rağmen çalışma alanı olan Isparta, Burdur ve Antalya illerinde de kendini göstermektedir. Büyük ölçüde yeni çeşitlerin, modern bağcılık tekniklerinin ve üretim teknolojilerinin üretim alanlarına yansıtılamaması, hastalık ve zararlılarla etkin mücadele yapılamaması, sulanan alanlarda sofralık üzüm yetiştiriciliğinin yapılmaması, ürün işleme ve pazarlama konularında yetersizlikler gibi sorunlar nedeniyle verim ve kalite kayıplarının yaşanması, üreticileri alternatif ürün yetiştiriciliğine yönlendirmektedir. Üretimde verim ve kalitenin artırılması, yeni teknolojilerin geliştirilmesi ve kısacası sahip olunan potansiyelin etkin olarak değerlendirilmesinde, giderek artan bilgi intiyacını karşılayacak yeni bilgilerin tarımsal araştırmalar yoluyla üretilmesi ve üretilen bilginin yayımcılar aracılığıyla çiftçilere ulaştırılarak benimsenmesi ve kullanılmasının sağlanması gerekmektedir. Ayrıca üreticilerin üretim faaliyetleri sırasında karşılaştıkları sorun ve intiyaçlar, yine yayımcılar aracılığıyla araştırma kuruluşlarına iletilmelidir. Çift tarafıı olması gereken bilgi akış sürecinde, süreklilik olmalıdır.

Yayım, tarımsal kalkınmada yeni tarım tekniklerinin doğru kullanımının sağlanarak, kaynakların etkin kullanılarak ve yaygınlaştırılarak tarımsal üretimin arttııımasında önemli bir etkendir (Özçatalbaş, 2009). Tarımsal yayımın başarısı ise, araştırmacı-yayımcı-üretici arasındaki iletişim ve işbirliğinin güçlü olması ile mümkündür. Araştırma-yayım-üretici arasındaki organik bağın güçlendirilmesinde en önemli şart bu işbirliğinin ve bağın kurumsallaştırılmasıdır. Üreticinin öncelikleri ve şartları dikkate alınarak dünyadaki gelişmeler doğrultusunda hedeflerin belirlenmesi ve araştırmacı ve yayımcının eş zamanlı hareket etmesini sağlayacak bir yapının oluşturulması önemlidir (Ottekin ve ark., 2010).

Tarımın giderek daha fazla bilgiye dayalı bir sektör halini alması, doğal kaynakların akılcı yönetimi ve sürdürülebilirliği ile ilgili kaygıların öne çıkması tarımsal yayımın önemini artırmakta, sektörün içinde yaşadığı ve dışında gelişen kimi koşullar tarımsal yayımda yeni yaklaşımları ve yeni arayışları gündeme getirmektedir (Kızılaslan ve Ünal, 2013).

Türkiye'de araştırma-yayım-çiftçi bağının güçlendirilmesi, kurumsallaşması ve yayımın etkin hale getirilmesi amacıyla "Tarımsal Yayım ve Uygulamalı Araştırma Projesi (TYUAP)", "Bölge Bilgi Alışveriş Toplantıları (BAV)", "Köy Merkezli Tarımsal Üretime Destek Projesi (KÖYMER/TARGEL)", "Tarımsal Yenilik ve Bilgi Sistemi" kapsamında "Bölge Grup Toplantıları (BGT) ve "İ Grup Toplantıları (IGT)", "Tarımsal Yayım Hizmetlerinin Desteklenmesi Projesi" ve özel sektöre dayalı danışmanlık sistemini geliştirmeye yönelik "Tarımsal Yayım ve Danışmanlık Hizmetlerinin Düzenlenmesine Dair Yönetmelik" gibi farklı proje ve yönetmelikler uygulamaya koyulmuştur.

Ancak bugüne kadar büyük ölçüde kamu tarafından yürütülen yayım hizmetlerinde etkin bir iletişim sağlanamamış, Tarım ve Orman Bakanlığı 2013-2017 Stratejik Planı Tarımsal Üretim ve Arz Güvenliği Stratejik Alanında yapılan GZFT (G: Güçlü Yönler, Z: Zayıf Yönler, F: Fırsatlar, T: Tehditler) Analizinde, "araştırma-yayımçiftçi zincirinin etkinliğinin yetersiz olduğu" vurgulanmıştır (Anonim, 2013a). 2013 yılında Tekirdağ'da düzenlenen "Vizyon 2023 Bağcılık Çalıştayı"nda da, yayım zincirinin etkinleştirilmesi konusuna dikkat çekilmiş, yüksek maliyet ve zaman gerektiren AR-GE çalışmalarından beklenen ekonomik, sosyal ve çevresel etkilerin sağlanması için yayım faaliyetlerinin büyük önem taşıdığı belirtilmiştir (Anonim, 2013b).

Bu çalışmada, Isparta, Burdur, Antalya illerinde bağ yetiştiriciliğiyle uğraşan çiftçi, yayım teşkilatı ve araştırma kuruluşlarının bağcılık eksenli ilişkilerinin belirlenmesi ve sektör paydaşları arasındaki işbirliğinin güçlendirilmesine yönelik öneriler geliştirilmesi amaçlanmıştır. Bu amaçla OGT toplantısı düzenlenmiştir. OGT nitel veri toplamada önemli bir işleve sahiptir. Amacı, belirlenen bir konu hakkında katılımcıların bakış açılarına, yaşantılarına, deneyimlerine, eğilimlerine, fikirlerine, duygularına, tutum ve alışkanlıklarına dair derinlemesine ve çok boyutlu nitel bilgi edinmek olarak ifade edilebilir (Yıldırım ve Şimşek, 2008, Baş ve ark., 2008). Görüşmelerde açık uçlu ve yorum gerektiren sorular sorulur (Baş ve ark., 2008). Sorular sohbet tarzına ve günlük dil kullanımına 
uygun ve teknik dilden arındırılmış olur (Kruger ve Casey, 2000). Sosyal bilimlerde tek başına ya da birebir görüşmeler ve anketler ile birlikte kullanılsalar da bu yöntem, aslında en sistematik veri toplama yöntemlerinden biridir.

\section{MATERYAL VE YÖNTEM}

Çalışmanın materyalini, Türkiye bağcılığında önemli yere sahip illerden olan Isparta, Burdur ve Antalya illerinde bağcılık konusunda faaliyet gösteren çiftçiler, kamu ve özel sektör yayımcıları (Tarım ve Orman Bakanlığı İl ve İlçe Müdürlüklerinde çalışan teknik personel, çiftçi örgütü temsilcileri-ziraat odaları, kooperatifler, birlikler vb., zirai ilaç, gübre, fidan bayi temsilcileri, üzüm pazarlamasında faaliyet gösteren kişi ve işletmelerin temsilcileri ve serbest tarım danışmanları) ile Üniversite Öğretim Üyeleri ve Araştırma Enstitüsü araştırmacı personellerinin katılımı ile gerçekleştirilen Odak Grup Toplantısından (OGT) elde edilen bilgiler oluşturmaktadır. Çalışmada ayrıca, konu ile ilgili istatistiki veri ve yayınlardan yararlanılmıştır.

Çalışmada Türkiye bağcılığında potansiyeli olan 3 ilde bulunan (Isparta, Burdur, Antalya) paydaşların katılımıyla, 2017 yılı içerisinde üç il için beraber yapılan OGT'na toplamda 20 kişi katılım sağlamıştır. Katıımcılara konu ile ilgili olarak belirlenen soruların yöneltilmesi ile oluşturulan ortamda tartışılması sağlanmıştır. KatıIımcılara Tablo 1'de belirtilen sorular yöneltilerek OGT yürütülmüştür.

Tablo 1. OGT'lerde Katılımcılara Yöneltilen/Tartışılan Sorular

\begin{tabular}{|c|l|}
\hline No & Sorular \\
\hline 1 & Birbirimize ihtiyacımız var mı? Ne düşünüyorsunuz? \\
\hline 2 & Birbirimizden ne bekliyoruz? \\
\hline 3 & Birbirimizin sorunlarını ne kadar çözebiliyoruz? \\
\hline 4 & Birbirimizle aramızdaki ilişkiler nasıl? \\
\hline 5 & Birbirimizle ilişkilerimizin zayıfığı neden kaynaklanıyor? (Güçlü ise neden?) \\
\hline 6 & Çalışmalarımızdaki önceliklerimiz nelerdir? \\
\hline 7 & Yenilikler nasıl daha hızlı yayılabilir? \\
\hline 8 & İlişkiler nasıl daha güçlendirilebilir? \\
\hline 9 & İlişkileri güçlendirmek için kimler ne yapabilir? \\
\hline 10 & Bu konuda kimler neler yapabilir? \\
\hline 11 & Araştırmacılara çözümü için aktarmak istediğiniz sorun/sorunlarınız nelerdir? \\
\hline
\end{tabular}

\section{BULGULAR VE TARTIŞMA}

Isparta, Burdur ve Antalya illerinde bağcılıkta yayım etkinliğinin güçlendirilmesi amacıyla düzenlenen OGT'nda, katılımcılara Tablo 1'de yer alan sorular sırasıyla yöneltilmiş ve katılımcıların konu ile ilgili görüş ve önerileri birleştirilerek aşağıda sırasıyla verilmiştir.

SORU 1: Birbirimize ihtiyacımız var mı? Ne düşünüyorsunuz?

Araştırmacı, yayımcı ve çiftçiler, her biri makinenin bir parçası olduklarını, birbirlerine her zaman ihtiyaç duyduklarını ve karşılıklı olarak sürekli iletişim halinde sorunların çözülmesi gerektiğini ifade etmişlerdir.

SORU 2: Birbirimizden ne bekliyoruz?

Çiftçiler;

- Araştırmacılardan daha çok bağ hastalık ve zararıları (özellikle kurşuni küf, mildiyö, külleme ve salkım güvesi ve bölgeye uygun anaç/çeşit adaptasyonu) konusunda araştırma yapılmasını ve sonuçların yayımcılar aracılığıyla kendilerine iletilmesini,

- Dikim sıklığı ve budama terbiye sistemleri konusunda eğitim toplantısı düzenlenmesini,

- Bölgede hangi üzüm çeşitlerinin üretildiğine yönelik bir fizibilite çalışması yapılmasını talep etmektedirler.

Yayımcılar;

- Çiftçinin talep etmediği bir bilginin yayımcı tarafından iletilmesinin hiçbir etkinliğinin olmaması nedeniyle yayımcılar, çiftçilerin bilgi eksikliği hissettikleri konular ve karşılaştıkları sorunların çözümü noktasında kendilerinden talepte bulunmalarını,

- Çiftçilerin duymaktan ziyade, gördüğünü daha çabuk benimsemeleri nedeniyle araştırmacıların çalışmalarını çiftçi koşullarında yürütmelerinin daha etkili olacağını,

- Araştırmacıların, hastalık ve zararlılarla entegre mücadelenin önemli bir parçası olan tahmin ve erken 
uyarı sisteminin geliştirilmesi ve etkinliğinin artırılması yönünde çalışmalar yürütmelerini,

- Üzüm üretim maliyetlerini düşürmeye yönelik çalışmalar yürütmelerini,

- Araştırmacıların yaptıkları çalışmaların sonuçlarının kendilerine iletilmesini,

- Araştırmacılara ulaşmada prosedür ve bürokrasi nedeniyle yaşanan sorunların (örneğin, numune gönderirken) iletişimde daha pratik bir sistem oluşturularak giderilmesini,

- Yayımda önemli bir rol oynayan zirai ilaç bayilerinin, kamu yayımcıları aracılığıyla düzenlenen eğitim toplantıları vasıtasıyla, bitki sağlığı ve zirai mücadele konularında bilinç düzeylerinin artırılmasını talep etmektedirler.

Araştırmacılar;

- Çiftçi ve yayımcıların karşılaştıkları sorunları kendilerine iletmelerini,

- Üniversite ve araştırma kuruluşlarında çeşit/anaç adaptasyon çalışmaları da dâhil olmak üzere yapılan çalışma sonuçlarının en kısa sürede yayımcılar aracılığıyla çiftçilere ulaştırılmasında iletişim kaynaklı sorunların çözülmesini beklediklerini ifade etmişlerdir.

Ayrıca katılımcılar, Tarım ve Orman Bakanlığı'nın;

- Üretim planlaması yapması ve çiftçilerin bu planlamaya göre üretim desenini oluşturması,

- Yayım konusunda başarısını sorgulaması ve yeniden yapılanmaya gitmesi,

- Araştırmacı-yayımcı-çiftçi arasındaki iletişimi geliştirmeye yönelik online bir sistem kurması,

- Çiftçilerin, İI-İlçe Tarım ve Orman Müdürlüklerine her zaman gitmelerinin çok zor olması nedeniyle kamuda tarım danışmanlığı sistemini (TARGEL) yeniden hayata geçirmesi gerektiğini belirtmişlerdir.

SORU 3: Birbirimizin sorunlarını ne kadar çözebiliyoruz?

- Çiftçiler, karşılaştıkları sorunları, genel olarak İı-i̇lçe Tarım ve Orman Müdürlüğü aracılığıyla çözebildikleri görüşünü taşımaktadırlar.

- Katılımcılar, çiftçilerin teknik sorunlarının çözülebilir nitelikte olduğunu, ekonomik kaynaklı sorunlarının ise çözümünün zor olduğunu belirtmişlerdir.

- Ayrıca internetin hayatımıza girmesiyle artık iletişimin daha kolay olduğunu ve sorunların bu sistemle daha hızlı çözülebileceğini ancak çiftçilerin henüz bu mekanizmayı çok da iyi kullanamadıklarını ifade etmişlerdir.
SORU 4: Birbirimizle aramızdaki ilişkiler nasıl?

- Üniversite ve araştırma kuruluşlarında yapılan araştırma sonuçlarının yayımcı ve çiftçilere ulaştırıması noktasında bir kopukluk yaşanmaktadır. Enstitülerde yürütülen araştırma sonuçları İI Müdürlükleri ve Eğitim Yayım ve Yayınlar Dairesi Başkanlığı'na bildirilmesine ve yılda 2 kez Bölge Grup Toplantısı yapılarak bu toplantılarda yayımcı ve çiftçilere ulaştııılmaya çalışılmasına rağmen iletişimde kopukluklar mevcut ve halen araştırma sonuçları çiftçi ve sahadaki konu uzmanı yayımcıya ulaşmamaktadır.

- Araştırmacılar, araştırma faaliyetlerinin, çiftçiler tarafından önemsendiğini ve desteklendiğini, araştırmacı-çiftçi işbirliğinde sorun yaşanmadığını ifade etmişlerdir.

- Ancak yayımcılar, araştırmacıların sahaya geldiklerinde ve çiftçilerle çalışma yapmak istediklerinde, kendileriyle iletişime geçmediklerini, doğrudan çiftçilerle iletişime geçtiklerini belirtmişlerdir. Oysa araştırmacıların o bölgedeki yayımcılar aracılığıyla çiftçilerle iletişime geçmesinin ve işbirliği yapmalarının daha sağlıklı olacağı vurgulanmıştır.

- Yayımcılar, araştırmacılarla iletişim kurmanın zor olduğunu ve prosedürlerden dolayı iletişimde aksaklıklar yaşandığını belirtmişlerdir.

SORU 5: Birbirimizle ilişkilerimizin zayıflığı neden kaynaklanıyor? (Güçlü ise, neden?)

- Yayımcılar, çiftçilerle ilişkilerinin sıcak ve samimi olduğunu, çiftçilerin kendilerine kolaylıkla ulaşabildiklerini, kurumlarında kendilerini rahat hissettiklerini ve bu nedenlerle ilişkilerinin güçlü olduğunu, meslek özelliğinden dolayı çiftçilerden kopmalarının mümkün olmadığını ifade etmiş̧lerdir.

- Yayımcı-araştırmacı ilişkilerinin güçlü/zayıf olmasının ise kişisel çabalara göre değişiklik gösterdiği, ilişkilerin daha kalıcı ve güçlü olması için kurumsal düzeyde bir sistem kurulması gerektiği belirtilmiştir.

- İ/IIlçe müdürlüklerinde konusunda uzman yayım personeli, tayin vb. görev değişiklikleri nedeniyle sürekli değiştiğinden dolayı, kurulan iletişimde kopukluklar yaşanmakta ve yayım hizmetleri sağlıklı yürütülememektedir.

- Çiftçiler, ilaç bayileriyle daha hızlı iletişime geçtikleri ve sorununu daha kolay çözebildikleri için ilaç bayilerine gittiklerini ve kamudaki yayımcıya intiyaç duymadıklarını belirtmişlerdir.

\section{SORU 6: Çalışmalarımızdaki önceliklerimiz nelerdir?}

- Çiftçilerin önceliği, yetiştirdikleri ürünü en iyi şekilde pazarlamak ve para kazanmaktır. Yayımcılar ise çiftçilerin önceliğinin, üretim planlaması yapmak yönünde olması gerektiğini belirtmişlerdir. 
- Yayımcılar, bölgede yetiştirilen ürün desenine ve resmi işler, yazışmalar, desteklemeler gibi gün içerisinde yapılması gereken işlere göre önceliklerini belirlediklerini ifade etmişlerdir. Özellikle ilçede çalışan yayımcılar, personel eksikliği nedeniyle her konu ile ilgilendiklerini, il müdürlüğündeki gibi personel arasında özellikli olarak bir konu dağılımının olmadığını belirtmişlerdir.

- Araştırmacıların önceliği, birim maliyeti düşürmeye yönelik çalışmalar yürütmek yönündedir.

- Üniversitedeki araştırmacılar, "çiftçinin sorunu nedir" diye düşünmediklerini çünkü bu faaliyetin akademik olarak bir karşılığı olmadığını ve bu nedenle önceliklerinin, akademik kariyer yönünde çalışmalar yürütmek olduğunu belirtmişlerdir.

- Dolayısıyla üniversitelerde daha çok teorik, araştırma kuruluşlarında ise pratiğe yönelik araştırma yapıldığını belirtmişlerdir.

SORU 7: Yenilikler nasıl daha hızlı yayılabilir?

Katılımcılar;

- Ürün bazında üretim bölgeleri oluşturulup kümelenme çalışmaları yapılarak,

- Çiftçi koşullarında demonstrasyon çalışmaları yapılarak veya örnek bahçeler kurularak çiftçilerin yenilikleri yerinde görmesi sağlanarak,

- Önder çiftçiler aracılığıyla yeniliklerin daha kolay yayılabileceğini belirtilmiştir.

SORU 8: İlişkiler nasıl daha güçlendirilebilir?

- Çiftçiler ürettikleri üründen daha fazla gelir elde ettiği takdirde yayımcı ve araştırmacılarla iletişime geçmeye ve iletişimini güçlendirmeye intiyaç duyacaktır.

- Araştırmacı-yayımcı-çiftçi arasında WhatsApp vb. gibi etkili ve güçlü iletişim ağı kurulabilir.

- Yayımcı, araştırmacı ile çiftçi arasında köprü görevi görmektedir. Bu yüzden yayımcıların devre dışı bırakılmaması ve daha etkin kullanılması gerekmektedir.

- Araştırmacı-yayımcı ve çiftçilerin bir arada olduğu periyodik bilgilendirme toplantıları yapılmalıdır.

SORU 9: İlişkileri güçlendirmek için kimler ne yapabilir?

- Arazi toplulaştırması yapılarak çiftçilerin işletme ölçeğini büyütmek ve organize tarım alanları kurmak, böylelikle çiftçilerin daha yüksek gelir etmesi ve yayımcı/araştırmacılardan bilgi talebinde bulunarak iletişimlerini artırmaları mümkün olacaktır.

- Yayımcıların çalışma konusu ile ilgili eğitim almaları sağlanarak mesleki donanımları artırılmalıdır.

- Taşrada bulunan yayım sorumlularının ve programlarının kalıcı olabilmesi için gerekli tedbirler alınmalıdır.
- Tarım ve Orman Bakanlığı taşra teşkilatları, yayım misyonunu ön plana çıkaracak şekilde yeniden yapılandırılmalı, devlet tarımsal yayımdan tamamen elini çekmemelidir.

- Tarım ve Orman Bakanlığı interaktif bir danışmanlık sistemi oluşturmalıdır.

- Çiftçilerin karşılaştıkları sorunlarla ilgili nereye müracaat etmeleri gerektiği konusunda bilgilendirilmeli, çiftçi gerekli yerlere kendisi müracaat ederek sorununu çözmeye çalışmalıdır (il-ilçe tarım, araştırma, üniversite vb.).

\section{SORU 10: Bu konuda kimler neler yapabilir?}

Bu soruya verilen cevaplar SORU 2 (Birbirimizden ne bekliyoruz?)'de ifade edildiği için burada tekrar yer verilmemiştir.

SORU 11: Araştırmacılara çözümü için aktarmak istediğiniz sorun/sorunlarınız nelerdir?

- Bağda anaç, çeşit adaptasyon çalışmalarının yapılması.

- Bağ hastalık ve zararıları ile ilgili (özellikle kurşuni küf, mildiyö, külleme ve salkım güvesi) çalışmaların yapılması.

- Dikim sıklığı, budama ve terbiye sistemleri konusunda eğitimlerin düzenlenmesi.

- Erken uyarı sisteminin geliştirilmesi.

- Bölgede hangi üzüm çeşitlerinin üretilebileceğine yönelik bir fizibilite çalışması.

- Üzüm üretim maliyetlerinin düşürülmesine yönelik araştırma çalışmasının yapılması.

\section{SONUÇ VE ÖNERILER}

Yeniliklerin çiftçilere nasıl aktarılacağı, teknolojinin götürüleceği hedef kitlenin seçilmesi, götürülmek istenen yeniliklerin uygun forma dönüştürülmesi, tarımsal yayım kuruluşlarının verimli çalışır hâle getirilmesi, tarımsal yayım ve uygulama sonuçlarının değerlendirilmesi gibi çeşitli konular tarımsal bilgi ve teknoloji akış sisteminde etkinliğin arttırılması için çözümü aranan sorunlardır (Röling, 1990).

Isparta, Burdur ve Antalya illeri için, bağcılıkta paydaşların yayım etkinliğinin güçlendirilmesi üzerine katılımcıların görüşlerinin tartışıldığı OGT sonucunda da, araştırmacı, yayımcı ve çiftçilerin birbirlerine her zaman intiyaç duydukları, yayım zincirinde sorunlar yaşandığı ve karşılıklı olarak sorunların çözülmesi gerektiği sonucuna ulaşılmıştır. Kaimowitz (1990); ulusal düzeyde tarım politikasını belirleyenlere somut öneriler götürülmesinin, yayımcı, araştırıcı, çiftçi örgütleri, özel teşebbüs gibi birimlerin birlikte uyumlu olarak çalışmalarının sistemin başarısını doğrudan etkilediğini bildirmiştir. 
Yeni tarımsal teknolojinin üretici kitlesine tanıtılması ve benimsetilmesi tarımsal yayım çalışmalarının ya da bu çalışmaları yürüten örgütlerin temel görevidir. Yayımın genel amaçlarından birisi tarımda verimliliği ve üretimi artırmaktır (Tatlıdil,1997). Tarımsal yayım amacına ancak araştırma kurumlarında elde olunan yeni bilgi ve teknikleri üreticilere benimsetebildiği oranda ulaşabileceğini bildirmiştir.

Enstitülerde yürütülen araştırma sonuçları İ Müdürlüklerine iletilmektedir. Ancak halen iletişimde kopukluklar mevcut olmakla beraber sonuçlar çiftçi ve sahadaki konu uzmanı yayımcıya ulaşmamaktadır. Hâlihazırda çiftçilerin; araştırma sonuçlarının yayımcılara ve kendilerine iletilmesi yönünde taleplerinin bulunması da bu durumun bir göstergesidir. Yayım zincirinde yaşanan sorunların birçok nedeni bulunmaktadır.

Ülkemizde tarımsal yayım hizmetleri büyük ölçüde kamu yayımı şeklinde Tarım ve Orman Bakanlığı tarafından yürütülmekte ve çiftçilerin beklentisi de bu doğrultuda devam etmektedir. Ancak Bakanlık taşra teşkilatında görevli yayım personelinin sürekli değişmesi ve personelin iş yoğunluğu başta olmak üzere çeşitli nedenlerle sahaya yeteri kadar çıkamamaları, yayımcıların araştırmacılarla iletişim kurmakta zorlanmaları ve prosedür/bürokrasilerden dolayı iletişimde aksaklıklar yaşanması yayım hizmetlerinin sağlıklı yürütülememesine neden olmaktadır. Bu durum, çoğu zaman çiftçilerin ilaç bayileriyle daha çabuk iletişime geçmesine ve sorununu daha kolay hallettiğini düşünmesinden dolayı kamudaki yayımcıya intiyaç duymamasına neden olmaktadır.

Yayım çalışmalarında etkinliği artırabilmek ve çiftçi davranışlarında olumlu değişiklikler yapabilmek için, uygulamalı çiftçi eğitimleri başta olmak üzere çiftçi ve yayımcıların eğitimi, yayımcı personelin araziye çıkmasını engelleyen masa başı mesaisinden kurtarılarak çiftçileri olabildiğince bağ arazisinde ziyaret etmeleri, araştırmacı ve yayımcının çiftçiye yönelik yayım programlarını birlikte hazırlamaları ve ortak çalışmalar içinde olması şarttır.

Ayrıca araştırmacıların, sahada bir çalışma yürütürken o bölgede faaliyet gösteren yayımcı personelle iletişime geçmeden direk çiftçilerle işbirliği yapmaları, yayım zincirinde yaşanan bir diğer sorun olarak karşımıza çıkmaktadır. Oysa araştırmacıların, bölgeye daha hâkim olmaları ve çiftçiyi daha yakından tanımaları nedeniyle öncelikle sahadaki yayımcı ile görüşmeleri ve yayımcılar aracılığıyla çiftçilerle işbirliği yapmaları daha sağlıklı olacaktır. Ayrıca çiftçilerin; araştırmacılardan daha çok bağ hastalıkları, çeşit ve anaç adaptasyon ve üretim maliyetlerini düşürmeye yönelik araştırma yapmaları ve sonuçlarının yayımcılara ve kendilerine iletilmesi, dikim sıklığı, budama terbiye sistemleri konusunda eğitimlerin düzenlenmesi yönünde talepleri bulunmaktadır. Çiftçilerin intiyaç duydukları bu konulara araştırma ve yayım faaliyetlerinde öncelik verilmesi ve yukarıda bahsedilen sorunların giderilmesiyle çiftçilerin verim ve kalite artışına paralel olarak gelirlerinde artış sağlanabilir, Türkiye bağcılığına yeni çeşitler kazandırılabilir ve bağcılıkta yeni üretim tekniklerinin kullanımı mümkün olabilir.

Bakanlık tarafından çıkarılan talimatlar ile son yıllarda yürürlüğe sokulan "Tarımsal Yenilik ve Bilgi Sistemi", "Elektronik Ortamda Tarımsal Yenilik ve Bilgi Paylaşımı" ve "Tarımsal Yeniliklerin Yaygınlaştırılması Yayım Projeleri" ile gerçekleştirilen faaliyetler/toplantılar yerinde izlenmeli ve denetlenmelidir. Bu yeni düzenlemelerin yayım etkinliğinin değerlendirilmesi ve uygulamada karşılaşılan sorunlara anında çözüm getirilmesi, araştırmacıyayımcı-çiftçi zincirini sağlamlaştırma noktasında ele alınması gereken önemli bir konudur.

\section{TEŞEKKÜR}

Bu çalışma, "Türkiye Bağcılığında Araştırma-YayımÇiftçi İlişkilerinin Belirlenmesi" adlı TAGEM (TAGEM/TEAD/17/A08/P03/002) projesi verileri kullanılarak hazırlanmıştır.

\section{KAYNAKLAR}

Ağaoğlu, S., Çelik, H., Çelik, M., Fidan, Y., Gülşen, Y., Günay, A., Halloran, N., Köksal, İ., Yanmaz, R. (1997). Genel Bahçe Bitkileri. Ankara Üniversitesi Ziraat Fakültesi Yayınları, Yayın no:1579, Ankara.

Anonim (2013a). Gıda, Tarım ve Hayvancılık Bakanlığı Stratejik Plan 2013-2017, Ankara, 103 s.

Anonim (2013b). Bağcılık Vizyon 2023 Eylem Planı, 26-27 Haziran 2013, Tekirdağ, 193-195.

Baş, T., Çamır, M., Özmaldar, B. (2008). Nitel Araştırma Yöntemleri. Ankara: Seçkin Yayınevi.

FAO (2020). http://www.fao.org/faostat/en/\#data/QC (Erişim tarihi: 20.07.2020).

Kaimowitz, D. (1990). Making The Link, Agricultural Research and Technology Transfer in Developing Countries. Published in Cooperation with the International Service for National Agricultural Research (ISNAR), Westview Press, London.

Kızılaslan, N., Ünal, T. (2013). Çiftçilerin Tarımsal Yayım Farkındalıklarının Belirlenmesi (Tokat/Erbaa Örneği). Gazios manpaşa Bilimsel Araştırma Dergisi, 5:1-19.

Kruger, R.A., Casey, M.A. (2000). Focus group: A Practical Guide for Applied Research (3rd ed.). Thousand Oaks, CA: Sage Publications, $157 \mathrm{p}$.

Ottekin, A., Karabak, S., Özkan, N., Bozdemir, Ç., Taşcı, R. (2010). Tarımda Araştırma-Yayım-Üretici İlişkisi ve Sorunları. Türk Tarım Dergisi, 196:28-30.

Özçatalbaş, O. (2009) Türkiye ve AB'de Tarımsal Yayım Sistem ve Yaklaşımlarına Bakış. AB ve Türkiye Arasındaki Sivil Toplum Diyaloğunun Çok Yönlü Geliştirilmesi Uluslararası Sempozyumu, Bildiri Kitabı, 5-8 Kasım 2009, Antalya. 
Röling, N. (1990). Extension Science, Information Systems in Agricultural Development. Cambridge University Press, Cambridge.

Tatlıdil, H. (1997). Tarımda Yeniliklerin Yayılması ve Benimsenmesi, Tarımsal Yayım ve Haberleşme Seminer Notları, Ankara.
TÜİK (2018). Türkiye İstatistik Kurumu, Bitkisel Üretim İstatistikleri, www.tuik.gov.tr (Erişim Tarihi: 18.01.2020).

Yıldırım, A., Şimşek, H. (2008). Sosyal Bilimlerde Nitel Araştırma Yöntemleri (6. Baskı), Ankara: Seçkin Yayınevi. 